\title{
Crisis Communication in Social Media Era
}

\author{
Kholoud Ben Said \\ Sultan Qaboos University, Palestine \\ Prepared for: \\ Dr. Darwish Almaharbi
}

\begin{abstract}
Over the last couple of decades, organizations have become more vulnerable to crises. Extensive research has been done to address crisis and risk communication (Houston et al., 2015). With the appearance of the social media era, an ongoing debate is raging about the effectiveness of using social media in crisis communication and how social media can be effectively utilized to mitigate the impact of crises on organizations. This article will provide a comprehensive appeal crisis, what are the needed skills to manage or lead crisis management processes. It also will illustrate how recently developed communication models such as situational crisis communication model (SCC) and social-mediated crisis communication model (SMCM) can be used to manage crises. In order to have a comprehensive overview of this topic, six articles will be analyzed and findings will be concluded.
\end{abstract}

Keywords: Crisis communication, leadership, social media era, situational crisis communication model (SCC), social-mediated crisis communication model (SMCM). 
MANAGEMENT , ECONOMICS AND HUMANITIES

July 23-25 2021

\author{
Stockholm, Sweden
}

\title{
Introduction
}

Over the last couple of decades, organizations have become more vulnerable to crises. Extensive research has been done to address crisis and risk communication (Houston et al., 2015). With the appearance of the social media era, an ongoing debate is raging about the effectiveness of using social media in crisis communication and how social media can be effectively utilized to mitigate the impact of crises on organizations. This article will provide a comprehensive appeal crisis, what are the needed skills to manage or lead crisis management processes. It also will illustrate how recently developed communication models such as situational crisis communication model (SCC) and social-mediated crisis communication model (SMCM) can be used to manage crises. In order to have a comprehensive overview of this topic, six articles will be analyzed and findings will be concluded.

\section{Crisis management}

Shaluf et al. (2003) defined a crisis as an abnormal state that involves high, exceptional jeopardy to firms, and it can turn into a catastrophe if it is not wisely managed. Crises are unpredicted and occur due to external purposes like disaster which could be made by a human or by nature or internal purposes like faulty products and frauds (Boin et al., 2013; Fiksel et al., 2015; Khiun Then and Loosemore, 2006; Warren, 2010).Organizational crises are highly complicated and vague events, these events demand timely responses and urgent decisions that result in organizational alterations (Pearson and Clair, 1998). The levels of risk involved in crises are high and immediate, and there is a possibility for continual loss (Seeger et al., 2003). Argenti (2002) noted that crisis triggers the challenges within the organization and for their stakeholder. They have complicated and far-reaching effects that could adversely impact the culture, resources, and functionality of organizations (Dutton et al., 1994; Taylor, 2010). The expected severity of the crisis is related to three different characteristics. The characteristics involve issue importance (what is the expected loss if no correction is taken), uncertainty, and immediately.

Leaders face a challenging task when they manage crises by making proactive preparation or taking preventive procedures (Fleming and Zhu, 2017). Crisis management is a proactive process through which distinct steps are executed before, during, and after a crisis occurs (Caywood and Stocker, 1993; Simola, 2005). It involves early identification and avoidance of a crisis that is imminent or arising (Mitroff, 2001). Researchers have noticed the appearance of warning signals in the prodromal phase (Fink, 1986; Shrivastava, 1993; Simola, 2005). Crisis management includes assessing possible action courses that are linked to stakeholders and the execution of short-term and long-term action plans (Mitroff et al., 1996; Ulmer and Sellnow, 2000). Different models contribute to the development of the crisis management field, the simplest model was proposed by Smith, three stages model that includes the pre-crisis stage, crisis stage, and post-crisis stage (Coombs, 2007, p. 9). Four-stage frameworks were proposed to provide more clarification and insight (Coombs, 2007). Recently, a notable emphasis on involving organizational culture that promotes learning was formed by Veil's model (2011). A comprehensive five-phase model was created by Pearson and Mitroff (1993). This model not only listed the five phases but also provided in-depth illustrations regarding how to conduct 
MANAGEMENT , ECONOMICS AND HUMANITIES

July 23-25 2021

\author{
Stockholm, Sweden
}

crisis analysis. Detecting signals, preparing/avoiding, restricting damage, recovering, and learning are the five stages in the previous model.

In a time of crisis, Shelton (1997) stated that organizations needed a leader rather than a manager, as leaders stress on innovation, consonance, and readiness, while managers stress on imitation and present continuity. Managers focus on the total line in the loss chart at the end of the period, while leaders focus on the horizon line. Structure, policies, supervision, and process are focus areas of management, whereas human relations and trust are the focus areas in leadership. During crises, true leaders emerge, despite the dominance of uncertainty and negativity; they are optimistic as they know how to solve the puzzle in their minds. In times of crisis, people have the willingness to accept any circumstance changes and difference creation, and this will be driven by leaders' optimism energy. Status quo changes and difference creation transform leadership from being a duty to inevitable responsibility and what is more important than performing the role is the reflection of leadership characteristics (Kadibesegil, 2008).

Cener (2007) mentioned some of the leader manager qualifications. These qualifications will help them to perform a significant role in crisis management. It involves catching and inspecting crisis signals, preparing and protecting against a crisis, and planning and organizing the crisis management process. Issuing efficient communication, making effective decisions, and employing power during the crisis management process are also essential skills. Savaneviciene et al. (2014) classified the significant leadership competencies into three groups. The groups are self-management competencies, business management competencies, and people management competencies. Leaders who have these competencies rapidly adapt to wavering situations, attain effective communication, and manage people efficiently. Other leadership competencies were stated by Wooten and James (2008), including making decisions, initiating and sustaining firm culture and capabilities, communicating, effectively managing stakeholders and people. On the other hand, past researchers pinpointed four essential leadership competencies .These competencies involve having an urgency feeling, vigorous emotional intelligence, and innovative problem-solving skills, besides being sensitive to communication (Betancourt et al., 2017; Tubin, 2017).

As mentioned earlier, crisis management challenges leaders, test their characters and their qualities, particularly their communication skills. All leaders have a unique style that distinguishes their organizational leading's approach. There are many ways to classify and categorize leadership styles. Each style suits a specific situation, hence there is no standardized leadership style that could suit any crisis, and when the wrong leader is chosen in the time of crisis, it can turn into a catastrophe. Directive leaders are decisive and powerful, embrace a take-charge approach, have clear anticipation, clearly communicate with people, and predict them to follow him without asking many questions. The previous leadership style, as mentioned in some articles can effectively manage internal crises when they occur. However, it may restrain the initiative as it demands adaptable organizations and creative actions. Transformational leaders are flexible, confident, and rational. They carefully listen to subordinates and involve them in making more conscious decisions. The diversity of transformational leaders' assumptions is because they adopt a strategic and detailed thinking approach. This leadership style is not suitable in crises where there is an extreme time crunch as it takes time to make a conscious response. 


\title{
$11^{\text {th }}$ INTERNATIONAL CONFERENCE ON
} MANAGEMENT , ECONOMICS AND HUMANITIES

July 23-25 2021

\author{
Stockholm, Sweden
}

Transactional leaders are intelligent, stick to rules and regulations. They place more attention on the small details of individuals. This leadership style is not appropriate for managing the dynamics of emerged crises. Hale, Dulek, and Hale (2005) noted that charismatic leaders' role is more significant in the response stage than in the prevention and recovery stage. On the other hand, Cognitive leaders have expertise and knowledge in particular fields, think strategically, and take decisions in a participative way. They lack interpersonal skills, which make them not suitable for managing external crises, and effective only in internal ones.

\section{The Role of communication in the crisis management process}

In crises, every organization should employ communication to stimulate public trust and support (Allen and Caillouet, 1994). The focus of a good deal of research is investigating the relationship between crises, communication strategies, and crisis perception (Schultz, Utz, and Göritz, 2011). Crisis communication includes gathering, processing, and dissemination of crisis-related information (Comb, 2010). According to Fearn-Banks (2007), crisis communication is a dialogue that occurs before, during, or after the crisis between the organization and public to lessen the possible reputational damage. For any organization, the most intangible and valuable asset is the reputation (Lyon and Cameron 2004).In the late 1990s, Fombrun defined organizational reputation as a perceptual characterization of an organization's past and future actions. Organizational reputation as defined by Combs (1990) concerned with the relational history that is associated with stockholders' expectations. Sim (2009) noticed that the formation of reputation depends on individuals' perception which is based on their prior experience.

Good Organizational reputation has intangible and tangible advantages (Doorley and Garcia 2011). The intangible advantage is the good feeling that customers and employees have about an organization; this feeling can be translated into tangible benefits such as magnetizing better candidates and gaining more profit (Doorley and Garcia, 2011). Other researchers also confirmed the crucial role that reputation plays in attracting highly qualified employees (Eccles et al., 2007) and determining loyalty and satisfaction levels (Helm, 2007). When a comparison is made between leading organizations, organizational reputation provides a comprehensive appeal of the organization to its main competitors (Fombrun, 1996). Moreover, having a good repetition makes organizations more favorable and resilient (Lyon and Cameron, 2004). As demonstrated by other research, reputation significantly impacts management style perception and decision-making (Yoon et al., 1993).

Assumptions state that the goodness of reputation is determined by the goodness of three factors. These factors are deeds, correlations, and communication (Aula and Mantere, 2008). A going debate between studies regarding how long it needs to build an organizational reputation, and how it is measured. Forming a reputation requires many good transitions over time (Nguyen and Leblanc, 2001). Fombrun and Van Riel (2004) declared that organizational reputation development is through the information that stockholders receive regarding an organization. The information is received by stakeholders' interactions, organizations' mediated reports such as advertisement and media news, and second-hand information from individuals (word of mouth, weblog). Second-hand information is considered critical in some crises, therefore the coverage of the media is a significant attribute in reputation management (Carroll, 2004; Carroll and McCombs, 2003; Meijer, 2004). During crises, organizational 


\title{
MANAGEMENT , ECONOMICS AND HUMANITIES
}

July 23-25 2021

\author{
Stockholm, Sweden
}

reputation faces serious threats (Barton, 2001; Sturges, 1994). According to some researchers, reputational threats are shaped by three factors. These factors include initial crisis responsibility, where there is a direct relationship between stockholders' attribution of crisis responsibility and organization reputational threat (Coombs, 1998; Coombs and Holladay, 1996, 2002, 2004), the second and third factors are crisis history and previous relational reputation.

When there is a threat to organizational reputation in crisis, crisis communication is considered the most significant aspect of crisis management, and today reputation is built using communication (Eisenegger, 2005; Seemann, 2008). The role of internal communication is eliminating gossips (Fearn-Banks, 2007), while external communication's role is to create a likable organizational image (Penrose, 2000). Therefore, the role of communication is influencing crisis and not just providing information regarding crises (Ko“hler, 2006; Zerfaß, 2004). Effective crisis communication can reduce unwanted messages and compensate for unpleasant feelings about the organization (Coombs et al., 2010, p. 338).

In 1996, Gonza 'les-Herrero and Pratt proposed a model for crisis communication management that included four systematic steps. Horsley and Barker (2002) developed a more detailed model was which consisted of six steps. The previous model is based on crisis timing classification, and it is only for the public sector and ignored the importance of crisis classification. Moreover, it viewed crisis communication as a circle rather than a linear process. Seeger (2002) stated that it is impossible to precisely predict how a particular crisis communication system works. As a result, the suggested communication strategies of researchers might be ineffective, and adjusting communication strategies to suit the current crisis would be better. The classification of crises is significant and forms a base for the chosen strategies. A recently developed approach to crisis communication is the Situational Crisis Communication Theory (SCCT), which is an integration of the rhetorical approach and attribution theory (Comb, 2007).In crisis communication research, SCCT has been one of the most predominant theoretical framework (Coombs, 2007;Ma and Zhan, 2016). It is suggested by the previous theory that there is a strong link between the rhetorical response and the attribution of responsibility of crises; for instance, denial of individuals is the most appropriate response for a victim crisis. Coombs (2007) noted that responsibility and strategy match is the premise of SCCT, which will mitigate the negative effects on reputation. The model also emphasizes the importance of media relations, and supposes that the crisis manager should take advantage of different media coverage (Coombs, 2007). SCCT neglects the impact of distinct channels or distinct sources.

The diversity of crisis communication is captured by Comb (2010), who designed a communication array. In this array, communication is divided into two groups that are managing information and managing meaning. The former group includes gathering, analyzing, disseminating information that is related to crises. Crisis managers should understand the information nature. They should know how to process and employ information to make an effective decision and how to cope with the crisis. Additionally, specific parts of information should be shared with distinct stakeholders who are affected by the crisis. On the other hand, the latter group is more concerned with reflecting the strategic nature of crisis communication and includes the effort to impact stockholders' perception regarding the crisis, an organization, and responses to crises. The second dimension of the array is three stages 
of crisis management, each cell of six cells will identify the utilization of crisis communication to attain a specific organizational outcome.

\section{The impact of social media on Crisis Communication}

There is a growing interest in crisis communication researches that view social media as a critical element (Lucinda and Jin, 2017), also concerning social media types that are employed in crisis communication such as Twitter, Blogs, and Facebook (Cheng, 2016). The persuasion and distribution of the public's information, along with the reputation of an organization are the outcomes of communication crisis are greatly impacted by the choice of channel (Schultz, Ultz, and Goritz, 2011), another hypothesis concerning the effect of "stealing thunder" which declared that the release of crisis information can make the organization less negatively evaluated (Coombs, Claeys, and Holladay 2017).

As mentioned by Lucinda and Jin (2017), Social media plays a significant role in creating unprecedented chances and challenges for organizations that employ crisis communication, also it can amplify and attenuate crisis. Organizations only have the choice of how to use social media in crisis communication, but they don't have the choice regarding whether to use social media or not (Jin, Liu, and Austin, 2014, p. 76). According to Veil et al. (2011). There are some changes in the crisis communication landscape, due to social media, these changes include the availability of easy-access and the low-cost platform, in traditional media, there is a one-way path of information follow, while social media provide more chances to share information and different points of view (Anderson, 2010).

The effectiveness of theoretical framework helped to address the impact of deploying social media in crisis communication, for instance, networked crisis communication model (Utz et al. 2013), value modeling (Freberg, Saling, Vidoloff, and Eosco 2013), online discourse, "subareans" on the crisis (Coombs and Holladay ,2014), modified and extended from SCCT (Coombs, 2007), and the social-mediated crisis communication model (SMCC) (Liu et al., 2011).SMCC has been the most dominant theory, that has guided other researchers that employed social media in crisis communication. The model was originally proposed as blogmediated crisis communication (BMCC) (Jin \& Liu, 2010), it illustrates the correlation among the organization, the key public, social media, traditional media, and offline word of communication before, during, and after crises. The first part of the model describes the ways used by the public to seek and distribute the information of crises, while the second part is concerned with how to use the first part to gain insight and communicate them to the public in an effective manner. Unlike SCCM, SMCC takes in its consideration the impact of information sources or used channels in managing crises.

\section{The Do and don't when employing social media}

Social media generally is different digital tools and applications that enable content exchange and interaction perception between the organization and the public (Wright and Hinson 2009). Social media is more dialogic, interactive, and quicker in promoting correlation as opposed to traditional media. Social media's distinct platforms include social networks (Facebook, google plus) which are the most well-known platforms, blogs (Tumblr), microblog (Twitter), Photo sharing (Instagram), video sharing (YouTube). Social media has a positive image in societies due to its characteristics which are the ability to convey messages immediately, with no 


\title{
MANAGEMENT , ECONOMICS AND HUMANITIES
}

July 23-25 2021

\author{
Stockholm, Sweden
}

existence for time and space boundaries. Moreover, the usage of social media doesn't need professional skills and it is considered a classless digital society.

The modern media tools have made the crisis more visual and interactive which enhanced preparedness and participation in crisis response (Veil et al., 2011, p. 112). According to some researches, some practices are highly recommended to be applied while using social media during crises. These practices include being respectful to the audience, treating people in the same way you wish to be treated, compassion and empathetic communication can show the real concern for the specific event, so crisis response can be humanized by open exchange (Veil et al., 2011, p. 112). Be honest and transparent in sharing information when it is available this will reduce the threats that could stem from the public turning to other resources (Veil et al., 2011, p.11). Be accountable, reliable, and truthful and seek credible collaboration with other partners or sources (Goldfine, 2011, p. 16), as a result, messages will be coordinated to the public in a consistent and accurate manner. In addition, a robust relationship will be established and developed with partners prior to the crisis and a relationship with the public should be built before crises happen and should be included in the organization's crisis management policies. Effective policies involve activities to prepare the public by educating them (Veil et al., 2011, p. 111). Timing and immediate responses in crisis are very significant, the first response is the most significant and is the determinant for what is going to happen later (Landeau, 2011).Organizations should meet media needs, and remain accessible for journalist since the public will hear about the crisis from the media (Goldfine, 2011, p. 17; Seeger, 2006). It is very crucial that the crisis communication department should stick to the organization's vision and strategies, and they should be aware of different social groups who differently interpret your messages.

On the other hand, the worst social media practices in crisis communication include speculation, posting personal opinion, or posting something that you are unsure about it or how it will be interpreted which will make the public disgrace the organization, and finally separate social media strategy form the other organizational strategies.

Researchers have contradicting reviews regarding the effective role of social media in crisis communication, some researchers were more optimistic such as Kim et al. (2012) noticed that the usage of social media in crisis management in the organization was more frequent than the traditional one. Utz et al. (2013) claimed that the types of crises have no direct impacts; instead, different social media channels like Facebook, Twitter, and newspaper strongly and directly affect crisis communication effectiveness. Schultz et al. (2011) also noted that fewer negative crisis responses were emerged with using the informational strategy of social media compared to traditional newspapers. Newspapers may be reliable to current issues, meanwhile, Twitter positively impacted secondary crisis communication and responses. On the contrary, other researchers claimed that social media may introduce new challenges such as organizational image management, media channel fragmentation, and the dynamic process of crisis communication (Gilpin, 2010; Liu and Fraustino, 2014; Moody, 2011). Organizations could face an issue in managing their image as the construction of the image is nonlinear, and the distinct dimensions of an organizational image could be addressed by each channel (Gilpin, 2010). 


\title{
MANAGEMENT , ECONOMICS AND HUMANITIES
}

July 23-25 2021

\author{
Stockholm, Sweden
}

\section{Discussion}

In this part in-depth analysis of six articles will be provided, it will also be compared with the proposed literature review. The first article is "The Impact of Utilizing Social Media as a Communication Platform During a Crisis Within The Oil Industry" by Nor Emmy Shuhada Derania, Prashalini Naidua and was published in 2015, the purpose of this article as the name suggests is to examine the effectiveness of the social media role in three stages of the crisis which are preparedness, response, recovery. This article is not concerned only with the oil industry, it also mentioned other cases that social media was used as a communication channel, such as in natural disasters (an earthquake, wildfire). The used methodology in this study is qualitative research. The three main questions that were asked (1) what is the pros and cons of employing social media as a communication channel when employing social media as a platform in crisis, (2)what its impact on organizational reputation and image,(3) name the most effective forms of social media that could be used by organizations to reach the affected public. Several cases have recorded the effective usage of social media in a natural disaster such as the Great-Quake Tsunami (2011) when the Japanese used Twitter for planning rescue operations, fundraising, and providing emotional support. Therefore, these cases were evidence of the effectiveness of social media role not only to mitigate the effect of crisis but also to adequately manage crisis and share knowledge (Yates \& Paquette, 2011). Another study was conducted by Wendling et al (2013) declared that social media's new forms such as Facebook and Twitter are considered as a chance for the organization to mitigate crises' effects and to spread knowledge and information. On the other hand, other cases stated how late response has damaged organizational reputation and image, and how other organizations have criticized as they failed to effectively utilize social media. This exactly agrees with what we have mentioned earlier regarding the role that social media could play. It also mentions three main factors that contribute to a successful utilizing of social media which are message content, used channel, and message delivery frequency, these factors confirm what was mentioned earlier in the do and don't practices when using social media. From my point of view that this article the ongoing debate concerning the effectiveness of social media role, but I wanted to see its role in real crises in the post-crisis or pre-crisis stage from what is mentioned in the article we can notice that the right actions during the crisis are the main determinant of organizational reputation, another point which worth to be mentioned is that this article focused mainly on the advantages of using social media without viewing more details about the disadvantages of using social media, plus it is only focused on Twitter and neglected the other forms of social media, so are we always required to state or sometimes silence is golden.

The following article "When is silence golden? The use of strategic silence in crisis communication" by Phuong D. Le, Hui Xun Teo, Augustine Pang, Yuling Li, Cai-Qin Goh and was published in 2019. This article declares the viability and the types of strategic silence that can be used in crises, the goal of this article is to fill the gap regarding the effective role of silence in crisis management, and that was done by analyzing eight different international crises to see where silence was strategically adopted by organizations, and whether the strategy worked. Silence is not considered as a strategy for one of the main crisis theories such as situational crisis communication theory, which was discussed previously in the literature review. Articles' findings challenge what we have mentioned previously regarding the necessity of the quick response of organization in times of crisis, or "steal thunder "from the 


\title{
$11^{\text {th }}$ INTERNATIONAL CONFERENCE ON
} MANAGEMENT , ECONOMICS AND HUMANITIES

July 23-25 2021

\author{
Stockholm, Sweden
}

public or media. Several questions were asked in the light of this issue such as in crises, what is the circumstances under which organizations keep silent, how does the silence of an organization intensify the crisis, what could lead an organization to break its silence, how does the organization do that and after the break, how could it impact organizational image. The findings of this article reveal three intention-based topologies of strategic silence which are delaying, avoidance, and hiding silence, the last two silence strategies adversely impacted post silence organizational image when the organizational silence was forcibly broken, meanwhile delaying silence is used to signal work-in-progress, and if it is successfully sustained and broken as it is planned, it will help the organization to restore its image with its primary stockholders. In my point of view, that is a case study as mentioned in its limitation, so it can't be generalized. I believe also that the widespread of different social media platforms made people less patient, more curious and believe anything that could be shared or posted do believe, the main determinant of the success of this strategy is the public and media when they contribute to decreasing information intensity.

The third article is, "How focusing positively on errors can help organizations become more communicative: An alternative approach to crisis communication ." It was written by Charlotte Simonsson, Mats Heide and was published in 2018. This article spots the light on how errors can be used as early detection of crises, therefore, there is an urgent need to develop internal crisis communication where organizations' culture, leadership, and learning are highly important in the development process. The findings of this article are based on an empirical sub-study on internal crisis communication. During the study, 37 qualitative semi-structured interviews are done with nurses, physicians, managers, and crisis management specialists within a Swedish university hospital. The interviews confirm that organizational culture is the main driver of error reduction (Ruchlin et al., 2004; Stock et al., 2006; Weick and Sutcliffe, 2007). Encouraging an open report of errors without any blame is critical to the success of this culture, as stated by Stock et al. (2006, p. 375). Leaders should facilitate error reporting, and they should consider errors as a significant source for organization development, also managers should facilitate and prize those who report for errors. This article considers that meta-message is the main driver for increased openness which assumes that the system or organization is responsible for errors, not individuals. It is striking to know that healthcare research confirms that communication is the main cause for around 70 percent of error (see Weaver et al., 2011). Weick and Ashford (2001) stated that communication is a root source of error, but it is also a significant tool for learning and reflection. Therefore, it is important that leaders discuss the most important reports with co-workers, a discussion will enable exchanging experience, learning, and sense-making. The article finds that error management has great importance only in the pre-crisis and post-crisis phase, so what is the role of error management during the crisis?. One issue that worth mentioning is neglecting the size of an organization, and focusing mainly on the health sector, where errors can most of the time unfortunately adversely affect an individual's health. These errors are mainly caused by internal factors, but when operating in the business market, there are lots of factors outside the business control that could affect the business. Also, the size and structure of organizations were neglected. Since this article is conducted in the health sector, timing is an important aspect of error management which is also neglected. The culture of the country is also not mentioned which has a great effect on the individual personality. The limitation of this article for me that this article can't be generalized to other organizations working in other business sectors. The Fourth conference paper is, 


\title{
$11^{\text {th }}$ INTERNATIONAL CONFERENCE ON
} MANAGEMENT , ECONOMICS AND HUMANITIES

July 23-25 2021

\author{
Stockholm, Sweden
}

"Strategy Map for The Crisis Communication" which was written by Jaroslava Kádárová, Bohuslava Mihalčová, Gabriel Kádár, and Marek Vida and was published in 2015. The main focus of this paper is on the link between the formulation of crisis communication description, and its implementation which is known as a strategic map. The strategic map is a logical and coherent architecture for explaining crisis communication strategy, it exhibits the attainment of an organization's corporate objectives. During the crisis, a strategic map exhibits the attainment of stability which is considered the corporate objective. The paper also spots the light on the base of any strategic map which is discovering where the company creates its value, along with specifying the location and cause of the company's value. The components of the strategic map are strategic objectives for four main perspectives, strategic output indicators, and their drivers for all strategic objectives, the balance of strategic output indicators and drives, and the causal link between components. The most effective way to create the strategic map is represented by proceeding from top to down, and it begins with stating the destination station, identifying and clarifying the ways and means to achieve them, before that, a reevolution of the company's vision and value should be done. This paper also clarifies the requirement to have a successful communication which is a commitment for opencommunication and public relationship participation, performing two-way communication with internal and external audiences, harmonizing between what is said and what is done, having a clear definition of the enterprise's goals and objectives, and incorporating strategic communication perspectives and public relation in the development. When a crisis happens, it is primarily significant to perform a separation between formal and informal internal communication, it is required to control them, and most importantly to complement the appropriate information. This paper didn't specify a specific crisis communication model to be used, it ignored the types of crisis and the role of social media role in crisis communication.

The fifth article is called "Collaborative Crisis Management and Leadership in the Public Sector" which was published in 2018 by Naim Kapucu and Yusuf Ustun, the main purpose of this article is to find out the impact of leadership competencies on the effectiveness of crisis management. The outcomes of this article are based on a self-reported survey of executive public leaders in Turkey. The research asked questions were regarding the role of what the role of effective leadership in crisis and disaster management, how leadership's traits and skills of public administrators affect crisis leadership's effectiveness, and the influence of public administrators' leadership behavior on crisis management effectiveness. The article is based on the leadership action cycle model which was developed by Van Wart (2004), it is a leadership competency framework, and it mainly focuses on the public sector. This model classifies leadership behaviors into task-oriented, people-oriented, and organization-oriented. The results of this article show that there is a positive relationship between leadership traits and skills, and leadership's effectiveness, which supports what we have mentioned earlier that organizations need leaders during crises because of the effective role that they play. Most survey respondents agreed that the self-confidence, clear decision, flexibility, fast diagnosing, and effective communication are important leadership traits in crisis, most of the previous traits agreed with what was mentioned in the literature review. Additional traits such as the ability to utilize information and communication technologies (ICT) to choose appropriate communication channels and methods were added by this article as needed leadership traits. Regarding taskoriented leadership behavior, most respondents supported problem-solving, whereas managing innovation and creativity was less supported and that strike us and contradict what we have 


\title{
MANAGEMENT , ECONOMICS AND HUMANITIES
}

July 23-25 2021

\author{
Stockholm, Sweden
}

stressed previously in the literature review considered innovation and creativity are essential aspects during the crisis. Concerning people-oriented leadership behaviors, the respondents stressed the importance of rewards to motivate individuals and the perception of fairness, the previous behaviors are part of people management behaviors that mentioned earlier. About Organization-oriented leadership behaviors, decision making, and the constant exchange of information, and following up the latest trends were the most supported behaviors. But the main question after discussing this article" is there a difference between leaders' role in the private sector and public sector and their needed skills and trait needed in crisis management ".

The last article is "Exploring the relationship between corporate reputation and the public's crisis communication on social media" and it was published in 2018 by Bowen Zhenga, Hefu Liua, and Robert M. Davisonb. This article aims to view how social media opened the doors for the public to participate in the decision process related to secondary crisis communication (SCC). The Article's outcomes are based on a survey conducted in China after a real crisis, they are consistent with what we have found regarding the impact of the crisis on the corporate organization reputation and it adds public is less likely to point out less reputed firms' defects than highly reputed firms (Helm and Tolsdorf, 2013).In crises, the Public who like the firm is less likely to participate in the SCC, thus consumer loyalty is another factor that could influence an organizational reputation which was not highlighted earlier. The findings also spot the light on the contribution of culture to social media climate effects on the correlation between morality violation and SCC. The negative comments snowballing on social media can place the firm in danger during a crisis and when the public's comments perceive more support, they are more likely to post their opinion. The only limitation is that culture played has a great influence on how the public communicates, so it can't be generalized. The only raised question is what a corporation should do in this situation and what other factors other than customer loyalty can help the corporation in this regard. The findings of the discussion can be summarized as follows, managing a crisis needs some capabilities that leaders should have such as being self-confident and flexible, along with their ability to make the right decisions that are consistent with the company's visions and values. The second outcome is that social media has a great influence on crisis communication models, and it should be used carefully as it greatly influences organizational image and reputation.

\section{Conclusion}

There is an increased focus on the proactivity of crisis management and the effectiveness of crisis communication, as they are considered the cornerstones of crisis resolution. It is noted also that there is a growth of social media usage which has a great impact on crisis communication. This article addressed crisis management and the mandatory traits that leaders should have .Our finding highlighted the impact that social media have on crisis communication and how social can be used properly to maintain the reputation and image of the organization during crises. 


\section{References List:}

- Bhaduri, R., 2019.'Leveraging culture and leadership in crisis management'. European Journal of Training and Development, 43(5/6), pp.554-569.

- Derani, N.E.S., and Naidu, P. (2016). 'The Impact of Utilizing Social Media as a Communication Platform during a Crisis within the Oil Industry'. Procedia Economics and Finance, 35, pp.650-658.

- Kádárová, J., Mihalčová, B., Kádár, G. and Vida, M. (2015). 'Strategy Map for the Crisis Communication'. Procedia Economics and Finance, 23, pp.1119-1124.

- Kapucu, N. and Ustun, Y. (2017). 'Collaborative Crisis Management and Leadership in the Public Sector'. International Journal of Public Administration, 41(7), pp.548-561.

- Le, P.D., Teo, H.X., Pang, A., Li, Y. and Goh, C.-Q. (2019). 'When is silence golden? The use of strategic silence in crisis communication'. Corporate Communications: An International Journal, 24(1), pp.162-178.

- Liu, B., Pennington-Gray, L. and Klemmer, L. (2015). 'Using social media in hotel crisis management: the case of bed bugs'. Journal of Hospitality and Tourism Technology, 6(2), pp.102-112.

- Nätti, S., Rahkolin, S. and Saraniemi, S. (2014). 'Crisis communication in key account relationships'. Corporate Communications: An International Journal, 19(3), pp.234-246.

- Simola, S., 2014. 'Teaching corporate crisis management through business ethics education'. European Journal of Training and Development, 38(5), pp.483-503.

- Simonsson, C. and Heide, M. (2018). How focusing positively on errors can help organizations become more communicative. Journal of Communication Management, 22(2), pp.179-196.

- Thiessen, A. and Ingenhoff, D. (2011). 'Safeguarding reputation through strategic, integrated and situational crisis communication management'. Corporate Communications: An International Journal, 16(1), pp.8-26.

- Wisittigars, B. and Siengthai, S. (2019). 'Crisis leadership competencies: the facility management sector in Thailand'. Facilities, 37(13/14), pp.881-896.

- Xu, J. (2020). Does the medium matter? A meta-analysis on using social media vs. traditional media in crisis communication. Public Relations Review, 46(4), p.101947.

- Zheng, B., Liu, H. and Davison, R.M. (2018). 'Exploring the relationship between corporate reputation and the public's crisis communication on social media'. Public Relations Review, 44(1), pp.56-64. 